\title{
Hubungan Regulasi Emosi dengan Subjective Well Being pada Remaja dengan Orang Tua Bercerai
}

\author{
Hesti Sri Rahayu ${ }^{1}$ \\ Fakultas Psikologi, Unversitas Muhammadiyah Malang \\ e-mail: ${ }^{1}$ hesti.hesdot@gmail.com
}

\begin{abstract}
Adolescence is a period of tension as individuals begin to recognize the environment and recognize the people in surroundings. Nevertheless in Adolescence on broken home families. Adolescence need emotional regulation to know what they felt, and what they thought and able to evaluate the emotions experienced so as to act rationally not emotionally. So, it is possible if the adolescence with broken home family with high emotional regulation will have a high subjective well being. This study aims to determine the relationship of emotional regulation with subjective well being in teenagers on broken home family. The approach in this research is using a quantitative correlational. Moreover, the number of the subjects in this study were 100 teenagers who had divorced parents in age-range 13-21 years. The purposive sampling technique is used to gain the data. The researcher collect the data using Likert model scale. Then, the researcher used product moment correlation as the data analysis method. The research has uncovered that there is a positive significant relationship between family functioning and psychological well-being in divorced family teenagers, which is shown by probability value 0.000 $<0.005$
\end{abstract}

KEYWORDS Broken home, emotional regulation, subjective well being, teens

CITATION Rahayu, H. S. (2018). Hubungan regulasi emosi dengan subjective well being pada remaja dengan orang tua bercerai. Cognicia, 6, (1), 10-22.

Angka perceraian setiap hari semakin meningkat, hal ini bisa diakibatkan dari masalah internal maupun eksternal dari kedua pihak tersebut. Sepanjang 5 tahun terakhir, Kabupaten Malang menempati posisi kedua tingginya angka perceraian di Indonesia setelah Kabupaten Indramayu. Dilansir dari data yang ada di Pengadilan Agama (PA) Kota Malang tahun 2016, angka perceraian dari bulan Januari hingga Desember mencapai 3.013 kasus. Sedangkan angka perceraian sepanjang tahun 2017 meningkat hingga 3.094 kasus. Artinya, jika dibuat rata-rata, Pengadilan Agama Kabupaten Malang menerima 200 hingga 300 kasus perceraian per bulan.

Calhoun \& Acocella (dalam Lestari, 2012) menyatakan kegagalan dalam menjalin komunikasi suami dengan istri merupakan penyebab kegagalan rumah tangga. Keberhasilan melakukan komunikasi dan ada hubungan timbal balik dapat menjadi kunci kelanggengan rumah tangga. Hubungan timbal balik ini bersifat fleksibel namun memerlukan sikap dan cara berpikir yang terbuka. Maksud dari hubungan timbal balik tersebut adalah interaksi terus-menerus kepada diri sendiri, orang lain, dan lingkungannya. 
Menurut ringkasan literatur yang diungkapkan oleh Dagum (2002), peristiwa perceraian sering dianggap suatu peristiwa tersendiri dan menegangkan dalam kehidupan berkeluarga. Tetapi peristiwa ini sudah menjadi bagian kehidupan dalam masyarakat. Peristiwa perceraian dalam keluarga senantiasa membawa dampak yang mendalam. Kasus ini menimbulkan stres, tekanan, dan berdampak pada perubahan fisik dan mental. Keadaan ini dapat dialami oleh seluruh anggota keluarga.

Wasil (2014) mengungkapkan perceraian memiliki dampak psikologis pada anak. Anak merasa tidak aman setelah kehilangan salah satu anggota keluarganya karena mereka masih membutuhkan perlindungan dari orang tuanya, baik secara materi ataupun non materi (kasih sayang). Keadaan emosi seorang remaja dengan orang tua yang bercerai antara lain tidak terkontrol, marah, dan kecewa dengan kejadian yang telah terjadi, merasa kesepian karena ketika berkumpul anggota keluarga tidaklah lengkap, dan rasa sedih terhadap keluarganya. Menurut Mooney, Oliver, \& Smith (2009) remaja yang berasal dari keluarga bercerai memiliki well-being yang rendah dibandingkan dengan remaja dari keluarga utuh.

Well being biasanya diartikan dengan kesejahteraan atau kebahagiaan. Pada umumnya, well being terbagi menjadi dua yaitu subjective well being dan psychological well being. Psychological well-being atau kesejahteraan psikologis merupakan kemampuan individu dalam menerima dirinya untuk dapat mengontrol tekanan dari lingkungan eksternal dan merasakan kebahagiaan atas apa yang dimilikinya saat ini, dengan meningkatkan potensi yang ada sehingga memiliki tujuan hidup yang bermakna pada masa kini atau masa depan (Ryff, 1995). Ketika individu dapat merasakan kepuasan atau kebahagiaan, maka dirinya tidak hanya merasakan hal positif tetapi juga dapat meningkatkan potensi yang dimiliki sehingga dapat memiliki tujuan hidup yang bermakna. Sedangkan subjective well being atau kesejahteraan subjektif diartikan sebagai kebahagiaan, seperti evaluasi subjektif pada individu terkait dengan konsep kehidupan seperti kepuasan hidup, emosi yang menyenangkan, dan fulfillment atau kepuasan atas pencapaian hidup. Selain itu, kesejahteraan subjektif merupakan evaluasi kognitif dan tingkatan perasaan positif atau negatif, sehingga kesejahteraan subjektif lebih mengandung prinsip kesenangan (Diener, 2000).

Remaja yang berasal dari keluarga bercerai memiliki kesejahteraan subjektif yang rendah dibandingkan dengan remaja yang berasal dari keluarga utuh (Uchenna, 2000). Penelitian yang dilakukan oleh Werdyaningrum (2013) menyatakan, remaja dengan keluarga yang tidak utuh (broken home) memiliki nilai well being yang lebih rendah dibandingkan dengan remaja yang orang tuanya utuh. Remaja dengan orang tua bercerai memiliki rasa bersalah dan kesepian yang lebih tinggi dibanding mereka yang orang tuanya utuh. Penelitian Hassan, Yusoof, \& Alavi (2012) menjelaskan, situasi yang menyenangkan dalam keluarga dan lingkungan sekitar berpengaruh signifikan terhadap kesejahteraan remaja. Kesejahteraan yang baik akan hadir ketika situasi menyenangkan terjadi dalam keluarga dan lingkungan sosial remaja. Keberfungsian keluarga memiliki pengaruh yang sangat kuat dalam memengaruhi kesejahteraan remaja dan orang tua dalam menerima kebahagiaan.

Beberapa penelitian yang disimpulkan oleh Nakonezny, Shull, Rodgers (dalam Yuli 2015) menunjukkan bahwa terjadinya konflik di dalam rumah tangga akan berdampak pada ketidakbahagiaan diri anak secara psikologis. Perceraian merupakan 
salah satu penyebab terjadinya konflik rumah tangga. Hal ini menyebabkan anak secara tidak langsung memiliki rasa tidak aman secara emosional dan membuat anak menjadi lebih mudah memiliki emosi negatif, memiliki perasaan tertekan, sulit untuk mengendalikan emosi dan lebih berpikir pesimis.

Santrock (2003) menyatakan, memiliki anak remaja dalam keluarga merupakan tantangan bagi para orang tua, karena anak remaja sedang dalam perkembangan psikologis yang labil. Perubahan sosio-emosional remaja cenderung menanyakan identitas dirinya, merasa pemikirannya telah berubah tidak seperti masa kanak-kanak lagi, yaitu lebih logis dan abstrak, ingin bebas dari kontrol orang tua dan memiliki pendapat sendiri. Sujoko (2012) berpendapat, terdapat hubungan antara keluarga broken home dengan kenakalan remaja. Keluarga broken home memberikan sumbangan efektif sebesar 7,8\%, pola asuh orang tua $8,5 \%$, dan interaksi teman sebaya 5,6\% terhadap kenakalan remaja.

Salah satu dampak negatif dari perceraian bagi remaja adalah dirinya merasakan kesedihan dengan keadaan keluarganya, perasaan tidak nyaman, tidak aman (insecure), masalah emosional, tidak mampu mengendalikan emosi, dan kesejahteraan subjektif yang rendah (Prismati \& Wrastari, 2013). Ningrum (2013) mengatakan bahwa remaja yang tidak dapat menerima kenyataan bahwa orang tua telah bercerai cenderung tidak dapat mengendalikan emosi dengan baik serta mengalami kesulitan dalam bergaul. Remaja yang tidak dapat mengendalikan emosinya dapat dikatakan belum matang secara emosi atau regulasi emosi yang rendah, mereka yang memiliki regulasi emosi rendah cenderung kesulitan untuk berhubungan dengan orang lain.

Penelitian yang dilakukan oleh Kelly \& Emery (2003) membuktikan bahwa perceraian orang tua diyakini rata-rata menyebabkan berbagai masalah perilaku dan emosional pada anak dan remaja. Kaplan (2017) dalam tulisannya yang berjudul schoolspecific subjective wellbeing and emotional problems among high school adolescents mengatakan bahwa remaja yang memiliki subjective well being yang tinggi akan memiliki masalah emosi yang rendah, di mana remaja yang memiliki subjective well being tinggi mampu meregulasi emosi secara baik sehingga masalah emosi, somatisasi, dan konsep diri yang salah akan mampu ditangani oleh remaja.

Sheldon dan Eliot (dalam Nailil, 2009) mengatakan, salah satu faktor yang memengaruhi kesejahteraan subjektif siswa adalah emosi. Shourie dan kaur (2017) dalam tulisan subjective wellbeing and diffulcities with emotion regulaton among adolescents mengungkapkan bahwa remaja yang memiliki kesulitan meregulasi emosi lebih kecil memiliki kebahagiaan subjektif. Begitupun sebaliknya, hal ini dipengaruhi oleh pola asuh remaja tersebut. Permasalahan yang dialami remaja kebanyakan adalah ketidakstabilan emosi. Remaja akan mengalami berbagai pertentangan dalam kehidupan sehari-hari yang dapat memicu emosinya, sehingga berakibat fatal apabila remaja tidak bisa mengatur emosinya dengan baik.

Setelah melihat paparan di atas, peneliti tertarik mengangkat judul penelitian tentang "Hubungan Regulasi Emosi dengan Subjective well being pada Remaja dengan Orang Tua Bercerai". Berawal dari ketidakharmonisan keluarga yang sering kali terjadi pada kalangan remaja yang mengakibatkan anak pendiam, pemurung, malas di 
rumah, tidak dapat mengontrol emosi, dan cenderung berperilaku nakal. Peneliti mengambil subjek dari beberapa siswa SMP atau SMA di Kota Malang yang mengalami kasus perceraian. Peneliti mengharapkan meskipun ada beberapa anak yang dibesarkan dengan keluarga bercerai, mereka harus menjalankan kehidupan yang sebaik-baiknya. Manfaat yang diharapkan dalam penelitian ini adalah semoga dapat memberikan sumbangan ilmiah bagi perkembangan ilmu psikologi, khususnya psikologi sosial atau psikologi klinis terkait regulasi emosi dan subjective well being serta diharapkan dapat memberikan kontribusi yang positif bagi remaja dengan orang tua bercerai. Adanya regulasi emosi pada individu dapat meningkatkan subjective well being pada remaja sehingga dapat berperan secara optimal dalam kehidupannya, menjadi human strengths.

Adapun hipotesis dalam penelitian ini adalah adanya hubungan positif antara regulasi emosi terhadap subjective well being pada remaja dengan orang tua bercerai. Semakin tinggi regulasi emosi remaja dengan orang tua bercerai maka semakin tinggi pula subjective well being-nya. Begitupun sebaliknya, semakin rendah regulasi emosi maka semakin rendah pula subjective well being yang dimiliki oleh remaja dengan orang tua bercerai.

\section{METODE}

Desain penelitian ini menggunakan pendekatan kuantitatif. Penelitian kuantitatif menurut Arikunto (2010) merupakan penelitian yang dalam prosesnya banyak menggunakan angka-angka, mulai dari pengumpulan, penafsiran, serta penampilan data dari hasilnya. Penelitian ini merupakan penelitian korelasi. Penelitian korelasional adalah penelitian yang tujuannya melihat hubungan antara variabel atau beberapa variabel dengan variabel lain (Arikunto, 2010). Mc Creary (1998) menyatakan bahwa jika peneliti ingin mengkaji ada atau tidak adanya variabel yang terjadi secara natural berkorelasi denga variabel lain, maka desain korelasi dapat digunakan. Penelitian ini menguji antara dua variabel, yaitu regulasi emosi dan subjective well being.

Penelitian ini akan meneliti tentang hubungan regulasi emosi dan subjective well being pada remaja dengan orang tua bercerai. Populasi dalam penelitian ini adalah remaja laki-laki maupun perempuan dengan keluarga broken home berusia 18-21 tahun yang memiliki orang tua bercerai sebanyak 100 orang. Teknik yang digunakan dalam pengambilan subjek adalah kuota sampling. Menurut Sugiyono (2013), kuota sampling adalah teknik untuk menentukan sampel dari populasi yang mempunyai ciri-ciri tertentu sampai jumlah (kuota) yang diinginkan. Adapun kuota dalam penelitian ini berjumlah 100 remaja dengan keluarga bercerai.

Dalam suatu penelitian, peranan suatu variabel penelitan sangat penting. Winarsumu (2004) menjelaskan bahwa variabel merupakan suatu konsep yang mempunyai variasi atau keragaman. Adapun dua variabel yang digunakan dalam penelitian ini adalah variabel bebas yaitu regulasi emosi dan variabel terikat yaitu subjective well being.

Regulasi emosi adalah upaya remaja dengan orang tua bercerai untuk memonitor dan mengontrol kondisi emosional dan ekspresi dari segala keadaan dengan beradaptasi pada tuntutan atau situasi sosial yang berbeda. Adapun lima aspek regulasi emosi yang digunakan yaitu a) Pilihan situasi, terkait pengambilan 
tindakan dari remaja untuk membuat situasi lebih sesuai dengan harapan dapat membangkitkan emosi yang diinginkan ; b) Modifikasi situasi, terkait penyebaran perhatian agar tidak terfokus pada satu hal yang dapat menimbulkan emosi, misalkan mengalihkan situasi atau melakukan aktivitas lain; c) Pemberian perhatian, terkait cara seseorang mengubah perhatiannya dengan mengarahkan sebuah situasi untuk mengatur emosinya; d) Perubahan kognitif, yakni perubahan satu atau lebih dari penilaian remaja dengan cara mengubah bagaimana sebuah pemikiran, baik itu tentang situasi itu sendiri atau kapasitas untuk mengontrol kehendak suatu emosi; e) Modulasi reaksi, terkait upaya seseorang untuk mengurangi perilaku ekspresi emosi yang sedang berlangsung.

Variabel regulasi emosi diukur menggunakan skala regulasi emosi. Penyusunan item pada skala didasarkan pada teori Gross (2007) yang disusun dari lima aspek, yaitu pilihan situasi, modifikasi situasi, pemberian perhatian, perubahan kognitif, dan modulasi reaksi. Peneliti menggunakan skala ini karena skor reabilitasnya tinggi, yakni sebanyak 0,941 sehingga skala penelitian dapat digunakan untuk penelitian selanjutnya. Apabila skor realibilitas lebih besar dari 0,60 maka dapat dikatakan bahwa penelitian ini reliabel.

Variabel subjective well-being dalam penelitian ini merupakan penilaian menyeluruh remaja dengan orang tua bercerai yang melibatkan aspek kognitif dan afektif yang dibuat menjadi skala subjective well-being. Aspek kognitif merupakan hasil evaluasi terhadap kepuasan hidup individu yang terdiri dari kepuasan secara global dan dalam domain khusus, yang selanjutnya dicerminkan dalam penilaian terhadap kehidupannya. Aspek afektif merupakan hasil evaluasi perasaan individu, baik positif maupun negatif terhadap pengalaman yang dirasakan remaja dengan orang tua bercerai.

Variabel ini diukur menggunakan skala subjective well-being. Penyusunan item pada skala didasarkan pada teori Diener dan Lucas (2005) yang disusun berdasarkan komponen subjective well-being, yaitu aspek afeksi berupa afek positif (kegembiraan, keriangan, rasa suka cita, kebanggaan, dan kesenangan yang luar biasa), afek negatif (rasa bersalah, kesedihan, kecemasan, kemarahan, tekanan, kedengkian, dan depresi), dan aspek kognitif. Peneliti menggunakan skala ini karena reliabilitas skala yang tinggi, sehingga skala penelitian dapat digunakan untuk penelitian selanjutnya. Reliabilitas dalam penelitian ini diukur dengan metode Cronbach's Alpha yang apabila skor lebih besar dari 0,60 $(>0,60)$ maka dapat dikatakan reliabel. Adapun reliabilitas skala subjective well being sebesar 0,931.

Kedua instrumen pada penelitian ini diukur menggunakan skala likert yang disusun dengan item pendukung konsep (favorable) dan tidak (unfavorable). Pada setiap pernyataan terdapat empat alternatif pilihan jawaban, yaitu Sangat Setuju (SS), Setuju (S), Tidak Setuju (TS), Sangat Tidak Setuju (STS). Pada item favorable, akan diberi skor 4 untuk SS (Sangat Setuju), nilai 3 untuk (S) Setuju, nilai 2 untuk Tidak Setuju (TS) dan nilai 1 untuk Sangat Tidak Setuju (STS). Sedangkan pada item yang tidak mendukung (unfavorable), skor diberikan dengan sebaliknya, skor 1 untuk nilai untuk SS (Sangat 
Setuju), nilai 2 untuk (S) Setuju, nilai 3 untuk Tidak Setuju (TS) dan nilai 4 untuk Sangat Tidak Setuju (STS).

Secara umum penelitian yang akan dilakukan memiliki tiga tahap, yaitu persiapan, dimulai dari mencari referensi yang terkait dengan variabel penelitian yaitu regulasi emosi dan subjective well being. Selanjutnya, peneliti mencari subjek dari beberapa SMP atau SMA di Kota Malang. Kemudian, peneliti meminta izin terlebih dahulu kepada pihak sekolah (khususnya guru BK) untuk melakukan penelitian terhadap beberapa siswa yang sesuai dengan kriteria subjek peneliti. Peneliti akan mempersiapkan instrumen penelitian berupa skala regulasi emosi dan subjective well being. Skala tersebut disusun oleh peneliti berdasarkan lima strategi regulasi emosi yang dikemukakan oleh James Gross (2007). Skala subjective well being didasarkan pada teori Diener \& Lucas (2005) yang disusun berdasarkan komponen subjective well-being, yaitu aspek afeksi berupa afek positif (kegembiraan, keriangan, rasa suka cita, kebanggaan, dan kesenangan yang luar biasa), afek negatif (rasa bersalah, kesedihan, kecemasan, kemarahan, tekanan, kedengkian, dan depresi), dan aspek kognitif (kepuasan hidup). Setelah menyiapkan alat ukur, peneliti akan melakukan uji coba instrumen (try out) pada subjek homogen. Data-data hasil uji coba tersebut kemudian diolah untuk menguji validitas dan reliabilitas skala penelitan. Setelah itu peneliti menentukan item-item mana saja yang dapat dijadikan sebagai item dalam penelitian yang sebenarnya.

Selanjutnya adalah tahap penyebaran instrumen. Peneliti mulai menyebarkan instrumen pada beberapa SMP atau SMA di Kota Malang yang memiliki subjek sesuai dengan kriteria penelitian. Penyebaran instrumen penelitian dilakukan dengan memberikan skala regulasi emosi sebanyak 30 item, dan instrumen subjective well being sebanyak 20 item kepada remaja berusia 15-18 tahun dengan keluarga broken home.

Tahap terakhir adalah analisis. Setelah rangkaian persiapan dan penyebaran instrumen berakhir, peneliti memasuki tahap terakhir, yaitu menganalisis hasil dari keseluruhan proses penelitian. Data-data yang telah diperoleh diolah menggunakan program SPSS for windows ver. 21, yaitu analisis korelasional menggunakan uji koefisien korelasi. Uji koefisien dilakukan untuk mengetahui derajat hubungan antara variabel X (regulasi emosi) dengan variabel Y (subjective well being) pada remaja dengan orang tua bercerai. Setelah itu peneliti membahas keseluruhan hasil analisis tersebut dan mengambil kesimpulan penelitian.

HASIL PENELITIAN

Penelitian ini melibatkan 100 subjek yang diambil dari beberapa sekolah di Kota Malang.

Tabel 1. Data Subjek Penelitian

\begin{tabular}{|c|c|c|}
\hline Kategori & Frekuensi & Persentase \\
\hline \multicolumn{3}{|l|}{ Usia } \\
\hline 14 tahun & 6 & $6 \%$ \\
\hline 15 tahun & 12 & $12 \%$ \\
\hline 16 tahun & 36 & $36 \%$ \\
\hline 17 tahun & 27 & $27 \%$ \\
\hline 18 tahun & 17 & $17 \%$ \\
\hline
\end{tabular}




\begin{tabular}{l|c|c}
\multicolumn{1}{c}{ 20 tahun } & $\mathbf{1 0 0}$ & $\mathbf{1 0 0} \%$ \\
\hline Total & 37 & $37 \%$ \\
\hline Jenis Kelamin & 63 & $63 \%$ \\
$\quad$ Laki-Laki & $\mathbf{1 0 0}$ & $\mathbf{1 0 0} \%$ \\
$\quad$ Perempuan & & \\
\hline Total & 8 & $8 \%$ \\
\hline Sekolah & 12 & $12 \%$ \\
$\quad$ SMP Salahuddin Malang & 15 & $15 \%$ \\
SMA Salahuddin Malang & 10 & $10 \%$ \\
SMK Salahuddin Malang & 35 & $35 \%$ \\
SMK 3 PGRI Malang & 20 & $20 \%$ \\
SMK 1 Muhammadiyah & $\mathbf{1 0 0} \%$ \\
$\quad$ SMK 2 Malang & $\mathbf{1 0 0}$ \\
\hline Total
\end{tabular}

Pada tabel 1, dapat dilihat jumlah subjek di setiap kategorinya. Usia subjek terdiri dari 14 tahun sebanyak 6 orang (6\%), 15 tahun sebanyak 12 orang (12\%), 16 tahun sebanyak 36 orang (36\%), 17 tahun sebanyak 27 orang (27\%), 18 tahun sebanyak 17 orang $(17 \%)$, dan yang paling tua yakni 20 tahun sebanyak 2 orang (2\%). Berdasarkan kategori jenis kelamin, terdapat sebanyak 37 orang (37\%) subjek laki-laki dan 63 orang $(63 \%)$ perempuan. Untuk kategori sekolah, subjek yang berasal dari sekolah SMP Shalahuddin sebanyak 8 orang $(8 \%)$, SMA Shalahuddin sebanyak 12 orang $(12 \%)$, SMK Shalahuddin sebanyak 15 orang (15\%), SMK 1 Muhammadiyah sebanyak 20 orang (20\%), SMK 3 PGRI sebanyak 10 orang (10\%), dan SMK 2 Malang sebanyak 35 orang ( $35 \%)$.

Berdasarkan uji normalitas menggunakan uji kolmogorov-smirnov test pada 100 subjek, ditemukan bahwa 100 subjek memiliki nilai "normal", karena skor significantnya sebesar 0,938 dan lebih besar dari 0,05. Maka dapat disimpulkan bahwa data yang diuji berkontribusi normal.

Penelitian menunjukkan subjek yang memiliki regulasi emosi tinggi lebih banyak dibandingkan subjek yang memiliki regulasi emosi rendah, seperti pada tabel berikut.

Tabel 2. Regulasi Emosi

\begin{tabular}{llll}
\hline Kategori & Rentang Skor & Frekuensi & Persentase \\
\hline Tinggi & T. Score $>50$ & 54 & $54 \%$ \\
Rendah & T. Score $<50$ & 46 & $46 \%$ \\
\hline Total & & 100 & $100 \%$ \\
\hline
\end{tabular}

Berdasarkan skala regulasi emosi, diperoleh data bahwa subjek yang memiliki regulasi emosi tinggi lebih banyak dibandingkan subjek dengan regulasi emosi rendah. Hal tersebut diketahui bahwa dari 100 subjek yang dijadikan sampel terdapat 54 subjek yang dikategorikan memiliki regulasi emosi tinggi. Berarti 54\% dari total subjek yang dikategorikan ke dalam ketegori rendah berjumlah 46 subjek, sebanyak $46 \%$. 
Penelitian menunjukkan subjek yang memiliki subjective well beingtinggi lebih banyak dari pada subjek yang memiliki subjective well being rendah.

Tabel 3. Subjective well being

\begin{tabular}{llll}
\hline Kategori & Rentang Skor & Frekuensi & Persentase \\
\hline Tinggi & T.Score $>50$ & 55 & $55 \%$ \\
Rendah & T. Score $<50$ & 45 & $45 \%$ \\
\hline Total & & 100 & $100 \%$ \\
\hline
\end{tabular}

Berdasarkan skala subjective well being, diperoleh data bahwa subjek yang memiliki skor tinggi lebih banyak daripada subjek dengan skor rendah. Hal tersebut sesuai dari hasil yang diperoleh, yaitu dari 100 subjek yang dijadikan sampel, terdapat 55 subjek dengan kategori tinggi, yakni sebanyak 55\%. Subjek yang dikategorikan ke dalam kategori rendah terdapat 45 subjek, yakni sebesar $45 \%$.

Berdasarkan hasil uji analisis korelasi pearson product moment, diperoleh nilai probabilitas pada kolom sig (2-tailed) sebesar 0,000. Kedua variabel dikatakan berkorelasi atau berhubungan jika nilai sig (2-tailed) lebih besar dari 0,005 (Yamin \& Kurniawan, 2014). Karena nilai probabilitas 0,000 $<0,005$ maka dapat disimpulkan ada hubungan antara regulasi emosi dan subjective well being pada remaja dengan orang tua bercerai.

Arah hubungan kedua variabel dapat dilihat dari tanda positif atau negatif yang terdapat dalam nilai koefisien korelasi pearson (r). Tanda positif $(+)$ menunjukkan arah hubungan positif, di mana jika variabel bebas (x) tinggi maka variabel terikat (y) juga tinggi, begitupun sebaliknya (Sugiyono, 2013). Berdasarkan tabel 4, koefisien korelasi memiliki tanda positif $(0,522)$ yang berarti terdapat hubungan positif antara regulasi emosi dengan subjective well being pada remaja dengan orang tua bercerai. Regulasi emosi yang tinggi pada individu akan menghasilkan subjective well being yang tinggi juga, atau sebaliknya individu dengan regulasi emosi yang rendah akan memiliki subjective well being rendah.

Koefisien korelasi $(\mathrm{r})$ variabel regulasi emosi terhadap subjective well being berdasarkan hasil analisis pada tabel 4 adalah 0,515, yang berarti terdapat hubungan kuat antara regulasi emosi dengan subjective well being. Hubungan regulasi emosi dengan subjective well being berbanding lurus sebesar 51,5\%.

Koefisien determinasi $\left(\mathrm{r}^{2}\right)$ variabel regulasi emosi berdasarkan hasil analisis data di atas adalah 0,273, yang berarti sumbangan efektif dari regulasi emosi yang diberikan dalam subjective well being sebesar $27,3 \%$ sedangkan pengaruh faktor lain terhadap subjective well being sebesar $72,7 \%$.

\section{DISKUSI}

Penelitian ini menunjukkan ada hubungan positif antara regulasi emosi dengan subjective well being. Hal itu berarti semakin tinggi tingkat regulasi emosi, maka akan semakin tinggi pula subjective well being yang dimiliki seseorang, begitu sebaliknya. Semakin rendah regulasi emosi maka akan semakin rendah pula subjective well being yang dimiliki. Kontribusi dari subjective well being hanya sebesar $27,3 \%$ sehingga ada 
faktor lain terhadap subjective well being sebesar $72,7 \%$. Hal ini membuktikan bahwa hipotesis yang menyatakan ada hubungan positif antara regulasi emosi dan subjective well being remaja dengan orang tua bercerai dapat diterima. Dengan terbuktinya hipotesis penelitian ini, maka dapat dikatakan bahwa regulasi emosi berhubungan dengan subjective well being pada remaja dengan orang tua bercerai. Hal ini dapat dipahami bahwa regulasi emosi yang tinggi pada remaja dengan orang tua bercerai merupakan salah satu faktor individu mengalami subjective well being yang baik.

Terdapat lima aspek regulasi emosi menurut Gross (2007), yaitu (1) Situation Selection, yang menunjukkan tindakan bagaimana individu berahir pada situasi yang diharapkan, sehingga dapat menyebabkan emosi yang menyenangkan atau bahkan sebaliknya. Dengan kata lain, menentukan tindakan berdasarkan dampak emosional yang mungkin muncul. (2) Situation modification adalah usaha yang langsung dilakukan dalam memodifikasi situasi agar efek emosinya teralihkan. (3) Attentional deployment, merupakan cara seseorang mengubah perhatiannya dengan mengarahkan perhatian ke dalam sebuah situasi untuk mengatur emosinya. (4) Cognitive change mengacu pada perubahan cara seseorang dalam menilai situasi yang terjadi untuk mengubah signifikansi emosi, dengan mengubah cara berpikir mengenai situasi tersebut. (5) Response modulation merupakan upaya seseorang untuk mengurangi perilaku dari ekspresi emosi yang sedang berlangsung.

Uraian di atas mengindikasikan bahwa regulasi emosi sangat penting dimiliki oleh individu agar dapat menyikapi dengan baik situasi yang menimbulkan stres. Dari hasil penelitian ini, banyak remaja yang memiliki regulasi emosi yang tinggi dibandingkan yang rendah, namun perbedaan tersebut tidak jauh selisih frekuensinya. Berdasarkan hal tersebut maka penting bagi individu untuk terus meningkatkan regulasi emosi. Hal tersebut bisa dilakukan dengan cara mengolah emosi yang dimiliki, kapan mereka merasakannya dan bagaimana mereka mengalami atau mengekspresikan emosi tersebut ke dalam bentuk yang lebih positif. Hasil penelitian yang dilakukan oleh Dawenan, Akbar, dan Yuniarrahmah (2013) menunjukkan bahwa individu yang memiki regulasi emosi akan lebih memiki kepribadian hardiness atau tangguh. Ketangguhan merupakan suatu bentuk kepribadian yang menunjukkan kemampuan memanfaatkan situasi pembangkit stres sebagai kesempatan untuk pertumbuhan pribadi dan kualitas hidup secara umum. Dengan demikian maka individu akan memiliki kesejahteraan subjektif yang baik.

Menanggapi suatu hal secara terus-menerus dari tuntutan pengalaman dengan berbagai emosi melalui suatu cara yang bersifat spontan termasuk kemampuan untuk menunda reaksi spontan yang diperlukan bisa dibentuk melalui pengembangan regulasi emosi (Kostiuk \& Fouts, 2002). Lebih jauh dijelaskan individu yang mampu mengelola emosinya secara efektif memiliki daya tahan yang baik dalam menghadapi masalah.

Menurut Hassan, Yusoof \& Alavi (2012), keluarga yang berfungsi secara efektif dapat merangsang perubahan emosi remaja yang rapuh menjadi emosi yang positif, terlebih ketika keadaan atau situasi terasa menyenangkan. Keluarga sangat berperan dalam mencapai kesejahteraan subjektif remaja. Kesejahteraan subjektif individu dapat 
dipengaruhi oleh beberapa faktor, yaitu fisik, psikis, kognitif, sosial, dan lingkungan. Jika sesama anggota ikut serta dalam dan membangun hubungan positif antara keluarga, maka hal tersebut dapat membantu dalam meningkatkan kesejahteraan subjektif setiap individu.

Ryff (1989) menyatakan kesejahteraan subjektif individu dapat diartikan sebagai sebuah kebahagiaan dalam diri individu, sama halnya bagi mereka remaja dengan orang tua bercerai atau orang tua bercerai. Mereka merasakan kebahagiaan ketika orang tua tetap memberikan dukungan dan perhatian dan selalu menciptakan interaksi yang baik. Interaksi bersama keluarga memiliki peran dalam perkembangan remaja yang nantinya akan menjadi sebuah kebahagiaan sendiri, karena dengan perhatian tersebut mereka merasa dihargai dan dicintai oleh orang-orang di sekitarnya. Hal tersebut memiliki pengaruh yang baik kepada remaja, salah satunya dapat menjalin hubungan yang positif dengan orang lain dan mengolah emosinya dengan baik. Ketika remaja dapat menjalani hubungan yang positif dengan orang lain, hal tersebut memiliki dampak positif dalam mengatasi tekanan dalam dirinya.

Menurut An \& Cooney (2006), salah satu faktor yang memengaruhi kesejahteraan subjektif adalah dukungan sosial, bahwa mendapatkan arahan atau bimbingan dari orang lain dapat meningkatkan kesejahteraan subjektif. Dalam meningkatkan kesejahteraan subjektif, remaja tidak hanya membutuhkan regulasi atau pengelolaan emosi saja. Remaja juga mengharapkan dukungan sosial dan simpati atau pengertian dari orang-orang di sekitarnya, apalagi ketika mereka mendapat masalah. Hasil penelitian ini menunjukkan regulasi emosi memiliki kontribusi sebesar 27,3\% terhadap kesejahteraan subjektif pada remaja, terutama yang orang tuanya bercerai. Hal tersebut menunjukkan bahwa $72,7 \%$ kesejahteraan subjektif pada remaja dari keluarga broken home dipengaruhi oleh faktor lain di luar variabel regulasi emosi. Menurut Rathi \& Rastogi (2007), kesejahteraan subjektif dapat dipengaruhi oleh beberapa faktor, seperti kebermaknaan dalam hidup, ketika individu dapat merasakan bahwa hidupnya sangat berarti dan tidak merasakan tekanan dalam dirinya maka individu memiliki kesejahteraan hidup yang baik dibandingkan dengan individu yang tidak dapat merasakan bahwa hidupnya tidak berarti.

\section{SIMPULAN DAN IMPLIKASI}

Berdasarkan hasil penelitian, disimpulkan bahwa hipotesis diterima karena terdapat hubungan hubungan positif yang signifikan antara kepercayaan regulasi emosi dan subjective well being. Hal ini sesuai dengan hasil koefisien korelasi ( $\mathrm{r}$ ) yaitu 0,515, dan dengan nilai signifikan 0,000, yang menunjukkan regulasi emosi seseorang yang tinggi memiliki subjective well beiingyang tinggi, atau sebaliknya.

Implikasi dari penelitian ini yaitu diharapkan bagi remaja yang memiliki keluarga dengan orang tua bercerai dapat mengontrol emosinya dengan baik sehingga tidak merasakan kesedihan dan kesepian dan terhindar dari pergaulan bebas. Kepada orang tua, diharapkan untuk dapat selalu memberikan perhatian dan kasih sayang kepada anak-anaknya dan mendukung segala aktivitas remaja yang dirasa positif. Kepada pihak sekolah agar dapat dimasukkan sebagai informasi dan saran dalam memberikan bantuan kepada siswa yang menjadi korban perceraian terkait manfaat regulasi emosi dalam meningkatkan subjective well being. Bagi peneliti yang melakukan 
penelitian selanjutnya ada beberapa saran mungkin yang bisa dijadikan sebagai bahan pertimbangan, seperti mengaitkan subjective well-being dengan variabel lain selain regulasi emosi, misalnya self-compassion, pemaafan, motivasi belajar, kepribadian, prososial, dll. Peneliti selanjutnya juga dapat mengunakan subjek yang berbeda, misalnya remaja akhir usia dewasa awal.

\section{REFRENSI}

Ali, M. \& Asrori, M. (2006). Psikologi Remaja : Perkembangan Peserta Didik. Jakarta : Bumi Aksara Arikunto, S. (2010). Prosedur penelitian : Suatu Pendekatan Praktik (Ed. Revisi). Jakarta : Rineka Cipta

Coyle, C. T., \& Enright, R. D. (1997).Forgiveness interventions with post-abortion men. Journal of Consulting and Clinical Psychology, 65, 1042-1046

Dagun, S. M. (2002). Psikologi Keluarga. Jakarta: Rineka Cipta.

Dawenan, R. C. Akbar, S. N. \& Yuniarrahmah, E. (2013). Relationship between emotion regulation and hardiness in student athletes in Banjarbaru. Program Studi Psikologi, Fakultas Kedokteran, Universitas Lambung Mangkurat.

Dewi, P. S \& Utanuu, M. S (2008). Subjective well being anak dari orang tua bercerai. Jurnal psikolog, 35, 194-212

Diener, E. (2000). Subjective well-being : The science of happiness and a proposal for a national index. American Psychologist, 55, 34-43.

Diener, E., Lucas, R. E., dan Oishi, S. (2005).Subjective Well Being: TheScience of Happiness and Life Satisfaction. Handbook of Positive Psychology.NC: Oxford University Press

Diener, E., Sandvik, E., Pavot, W. (2009). Happines is the Frequency, Not the Intensity of Positive Versus Negative Affect. Social Indicators Research, 39, 213-231

Diener, E., Suh, E. (2000). Measuring Quality Of Life: Economic, Social, And Subjective Indicators. Social Indicators Research, 40, 189-216.

Diener,E., Larsen, R.J. (1993). The Experience of Emotional Subjective Well Being. Dalam Lewis,. Havilland (eds). Handbook of Emotion. New york : Guildford

Eid, M dan Larsen, R. J. (2008). The Science of Subjective Well-Being. New York: The Guilford Press

Eisenberg, N., Fabes, R. A., Guthrie, I. K., \& Reiser, M. (2000). Dispositional Emotionality and Regulation : Their Role in Predicting Quality of Social Functioning. Journal of Personality and Social Psychology, 78, 136-157.

Garawiyan, B (2007). Memahami gejolak emosi anak. Jakarta : Cahaya

Goleman, Daniel. (2004). Kecerdasan Emosional: Mengapa EI Lebih Penting Daripada IQ, Terjemahan oleh T. Hermaya. 2004. PT. Gramedia Pustaka Utama, Jakarta.

Gross, J. J. \& Thompson, R.A. (2007). Emotion regulation: Conceptual foundations. In Gross, J.J. (Eds). Handbook of emotion regulation. New York: Guilford Press

Gunarsa. (2000). PsikologiPraktis : Anak Remaja dan Keluarga. Jakarta : PT. BPK Gunung Mulia.

Hassan, A., Yusooff, F., \& Alavi, K. (2012). The Relationship between parental skill and family functioning to the psychological well-being of parents and children. International Conference on Humanity, History and Society, 34, 1-10

Hurlock, E. B. (2007). Psikologi perkembangan suatu pendekatan sepanjang kehidupan, edisi 5. Jakarta: Airlangga

Kaplan, Yilmaz (2017). School-specific Subjective Well Being And Emotional Problems Among High School Adolescents. Journal of postive Psychology Well being, 1, 1-9.

Kartono, Kartini (2007). Perkembangan Psikologi Anak. Jakarta: Erlangga 
Kartono, Kartini, (1992).Pathologi sosial 2 ( kenakalan remaja). Jakarta: Raja Grafindo Persada.

Kasiram, Mohammad. (2008). Metode Penelitian Kuantitatif-Kualitatif. Malang: UIN Malang Press.

Kelly, J. B \& Emery, R. E.(2003). Children's Adjustment Following Divorce: Risk and Resilience Perspectives. Family Relations, 2003, 52, 352-362

Lestari, S. (2012). Psikologi Keluarga (Penanaman Nilai dan Penanganan Konflik dalam Keluarga). Jakarta: Kencana.

Liliana, B. \& Nicoles, T. M. (2014). Personaliti, Family correlates and emotion regulation as wellbeng, predichors. Prospedia Social and Sciences, 159, 142-146

Mooney, A., Oliver, C. \& Smith, M. (2009). Impact of family breakdown on children's well-being. Institute of Education, University of London

Muchicht. M. S. 2013. "broken home" dari perspektif ilmu sosial. Majalah ar-rusyd, kantor jurusan dakwah stain Kusud, Jawa Tengah

Nayana, F. N. (2013). Kefungsian keluarga dan subjective well-being pada remaja. Jurnal Ilmiah Psikologi Terapan, 1, 230-244.

Ningrum, R.N. (2013). Perceraan orang tua dan enyesuaian diri reaja. Journal of applied psychology, 1, 69-79

Nurmalasari, Yanni. (2010). Hubungan Antara Dukungan Sosial Dengan Harga Diri Pada Remaja Penderita Penyakit Lupus. Makalah Tidak Di Terbitkan

Prastiti, A.D \& Rini, A.K. (2016). The relation of emotion regulation and subjecttive well being in adolescents students. Internasional conference on Healt and Well being, 111-118

Primasti, K. \& Wrastari A. (2013). Dinamika psychological wellbeing pada remaja yang mengalami perceraian orang tua ditinjau dari family confict yang dialami. Jurnal Psikologi Kepribadian dan Sosial 02-13

Ryff, C. D. \& Keyes, C (1995). The structure of psychological well being revisited. Journal of Personality and Social Psychology, 69(4), 719-72

Ryff, C. D. (1989). Happiness is everything, or is it?explorations on the meaning of psychological well-being. Journal of Personality and Social Psychology 1989, 57(6),1069-108

Santrock, J. W. (2003). Life-Span Development Perkembangan Masa Hidup Edisi ke lima Jilid II. Jakarta: Penerbit Erlangga

Santrock, J.W. (2003) Perkembangan Remaja. Edisi Keenam. Jakarta: Erlangga.

Shaffer, DR. (2005). Social and Personality Development. USA: Thomson

Shourie, Shruti \& Kaur, Harsmeet. (2017). Subjective Well Being and Diffucuties With Emotion Regulation Among Adolesce. Journal of psychology reseach, 12, 217-222

Sudarsono (1995). Kenakalan remaja. Jakarta: Aneka cipta

Sugiyono.(2013). Metode Penelitian Kuantitatif Kualitatif dan RED. Bandung: ALFABETA

Suhendi, Hendi \& Ramdani, Wahyu. (2001). Pengantar studi sosiolog keluarga. Bandung: Pustaka Setia

Sujoko (2012). Hubungan antara keluarga broken home, pola asuh orang tua dengan interaksi teman sebaya dengan kenakalan remaja. Journal psychology. http://psikologi05.files.wordpress.com/2012-02/naskah-publikasi.pdf

Sukarelawati, Endang. (2015, Januari 30). Angka Perceraian Meningkat Di Malang. Diambil Desember, 11, 2017, dari http://www.kompasmalang.com/angka/perceraian/malang.html

Uchenna, A. O. (2013). Single-parenting, psychological well-being and academic performance of adolescents in lagos, nigeria. Journal of Emerging Trends in Educational Research and Policy Studies, 112-117

Vratasti, I. G. M. (2016). Perbedaan Subjective Well-Being pada Perempuan Bali yang Menikah Sesama Wangsa dan Berbeda Wangsa. Jurnal Universitas Udayana,3, 519-528.

Wasil, S. K. W. (2014). Kondisi psikologi anak dari keluarga yang bercerai. Artikel Ilmiah Hasil Penelitian Mahasiswa Universitas Jember 
Werdyanngrum, P. (2013). Psychologycall well being pada remaja yang orang tua bercerai dan tidak bercerai(utuh). Journal Online Psychology, 01, 480-492

Wilson, J. W. (1999). Emotion Related Regulation: An Emerging Construct. Developmental Psychology, 35, $214-222$.

Winarsunu, Tulus. (2004). Statistik Dalam Peneltian Psikologi dan Pendidikan. Malang: UMM Press.

Yuli, Astuti.(2015). Subjective Well-Being Pada Remaja Dari Keluarga Broken Home:Naskah Publikasi. Surakarta. 